\title{
Academic Profile and College Preparedness of K-12 Graduates: The Case of the Indigenous Peoples (IPs) in the Northern Philippines
}

\author{
Rudolf T. Vecaldo ${ }^{1}$ \\ Antonio I. Tamayao ${ }^{2}$ iD \\ Maria T. Mamba ${ }^{3}$ \\ Jay Emmanuel L. Asuncion ${ }^{4}$ \\ Febe Marl G. Paat ${ }^{5}$ (D) \\ Editha S. Pagulayan ${ }^{6}$
}

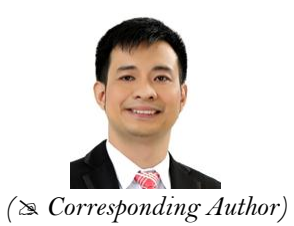

1,2, s,t,5,6 Cagayan State University, Tuguegarao City, Cagayan Province, Philippines.

'Email: rudvectop2@gmail.com Tel: +63926760953s

EEmail:tonitamavao@yahoo.com Tel: +639175211198

${ }^{3}$ Email: mariamamba@yahoo.com Tel:+639157044550

"Email:buds122386@yahoo.com Tel: +639278715946

Email:febgpaat@gmail.com Tel: +639175995400

${ }^{6}$ Email:pagulayaneditha@gmail.com Tel: +689985561989

\section{Abstract}

The indigenous peoples (IPs) are recognized as one of the disadvantaged social groups constituting Philippine minorities. While there have been several studies seeking to explain issues relating to IPs' participation in education, these have not adequately provided baseline data on the their academic profile and college preparedness, which are essential in understanding their effective transition from basic to tertiary education. Using descriptive-correlational design, this study investigated the association of academic profile and college preparedness of 1,860 IPs enrolled in a public university in the northern Philippines. The results revealed that the majority of respondents were college unprepared. Moreover, the level of preparedness differed significantly in terms of the type of senior high school (SHS) where they graduated, as well as the SHS track and strand they had taken. Kendall's tau- $b$ statistic results showed that IPs who had higher SHS grade point average (GPA), more academic and nonacademic awards, greater participation in organizations and more involvement in cocurricular activities tended to be more college prepared. In regard to educational practice, improving college preparedness with due consideration of the academic profile facilitates an increased ability for IPs to be admitted to college and to succeed without remediation in college foundation courses.

Keywords: College preparedness, Academic profile, Indigenous peoples, K-12 graduates, Philippines.

Citation | Rudolf T. Vecaldo; Antonio I. Tamayao; Maria T. Mamba; Jay Emmanuel L. Asuncion; Febe Marl G. Paat; Editha S. Pagulayan (2020). Academic Profile and College Preparedness of K12 Graduates: The Case of the Indigenous Peoples (IPs) in the Northern Philippines. Journal of Education and e-Learning Research, 7(4): 437-445.

History:

Received: 21 September 2020

Revised: 9 October 2020

Accepted: 11 November 2020

Published: 24 November 2020

Licensed: This work is licensed under a Creative Commons

Attribution 3.0 License $(\mathrm{oc})$ )

Publisher: Asian Online Journal Publishing Group
Acknowledgement: All authors contributed to the conception and design of the study. The authors sincerely thank CSU President, Dr. Urdujah A. Tejada and CHED Commissioner, Dr. Lilian de Las Llagas for making this study possible. Also, special thanks are extended to Ms. Aurora Mary Arugay and CSU DARE TO staff for their technical assistance.

Funding: This study received funding from the Commission on Higher Education through the DARE TO Research Grant (Commission En Banc Resolution No. 187-2019).

Competing Interests: The authors declare that they have no conflict of interests.

Transparency: The authors confirm that the manuscript is an honest, accurate, and transparent account of the study reported; that no vital features of the study have been omitted; and that any discrepancies from the study as of the study have been omitted;
planned have been explained.

planned have been explained.

\section{Contents}

1. Introduction...

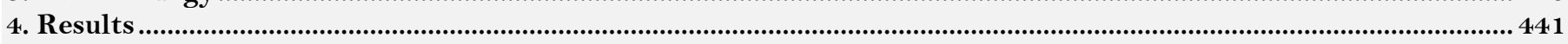

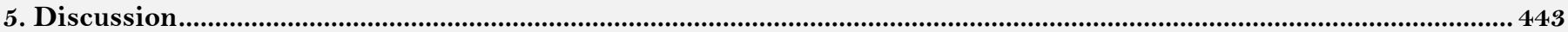

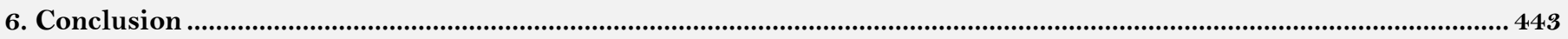

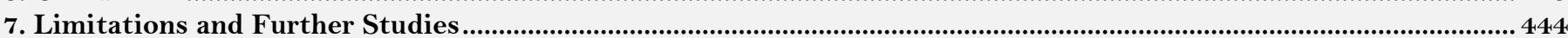

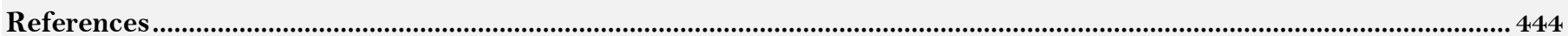




\section{Contribution of this paper to the literature}

This is a pioneering study that documents the link between IPs' academic profile and college preparedness in the northern Philippines. The study offers valuable insights into how education stakeholders may develop viable instructional initiatives to enhance IPs' academic profile and college preparedness for their effective transitioning from basic to tertiary education.

\section{Introduction}

Education has been viewed as a means of improving social mobility, changing people's lives in society (Bereketeab, 2020), and bolstering a nation's economy (Kingdom \& Maekae, 2013). It is a vehicle of empowering everyone to become productive members of a diverse and pluralistic world (Idris, Hassan, Ya'acob, Gill, \& Awal, 2012). With this, investment in education has become the governments' primary concern in developing citizens who are functionally literate, critical, creative, and socially responsible.

Nevertheless, not all individuals are given the chance to enjoy quality education (Torraco, 2018). Among those are indigenous peoples (IPs), who constitute society's non-dominant sector (Ganal, 2017). They usually consist of small populations relative to the mainstream culture and they have their distinct language, beliefs, traditions, norms, territory, and, most importantly, self-identity (Sicat \& David, 2016). They are resolute in upholding, nurturing, and passing on to their children the distinctiveness of their cultural identity, and the rights and entitlement to their ancestral domains.

The IPs are the most deprived and destitute social group because of the high incidence of illiteracy leading to unemployment (De Vera, 2007). The United Nations has documented that IPs generally face barriers in their desire to acquire knowledge, skills, and values that may enhance their potential for a better standard of living. Cultural discrimination, unfriendly school environment, and possible loss of identity are among the reported struggles of IPs in the educational milieu (Victor \& Yano, 2015). This scenario should not be the case, since IPs also form part of any country's human resources. Their fundamental rights to quality of life and education must be protected and preserved by the state. They simply need empowerment to fully realize their full potential (United Nations Development Programme, 2010).

In the Philippines, $10-15 \%$ of Filipinos belong to indigenous groups in 65 out of 80 provinces (Cariño, 2012). Most are found on the margins of society. Their underdevelopment has been attributed to the fact that the majority did not finish schooling. Providentially, in recognition of this social issue, the government created the National Commission on Indigenous Peoples (NCIP) and enacted the Indigenous Peoples Rights Act (IPRA) in 1997. These serve as a foundation for protecting IPs' rights, specifically those regarding identity, territory, and education (Cornelio \& De Castro, 2016; United Nations Development Programme, 2010).

Attuned to the reforms thus instituted, several governmental and nongovernmental agencies have started to formulate educational programs (Wa-Mbaleka, 2013) to help IPs gain functional literacy and eventually earn college diplomas. In regard to this, certain measures, such as the IP Education Framework for basic education and integration of IP studies in higher education, were instituted to increase awareness, address IPs' academic issues, and foster their educational aspirations. More than that, there is now a growing enthusiasm among IP groups to strive vigorously in the pursuit of higher education degrees because they have seen the individual and social advancement attached to this (Adonis \& Couch, 2017).

With the recent graduation of the second batch from the K-12 program in the Philippines, little is yet known about the essential educational constructs on IPs' transition from basic to tertiary education. While there have been studies (Adonis \& Couch, 2017; Reyes, Mina, \& Asis, 2017) seeking to explain issues relating to participation of IPs in education, these did not provide solid baseline data on their academic profile, including an understanding of their college preparedness. Hence, investigating the link between the academic profile and college preparedness of IPs would offer valuable insights into how education policymakers and curriculum implementers might develop viable interventions and IP-driven instructional initiatives to enhance IPs' academic standing and college preparedness for their effective transitioning from basic education to college life.

\section{Literature Review}

\subsection{Status of Education of IPs in the Philippines}

The indigenous peoples are known for their diverse beliefs and practices, which are clearly seen in their lifestyles. The formalization of education brought by the Spaniards, and especially by the Americans, has alerted a new consciousness - in particular, with the educational system (Pe-Pua \& Protacio-Marcelino, 2000). Moreover, globalization has further imposed a threat and forced them to adapt to a formalized, institutionalized educational system, somehow enforcing upon them a new consciousness distant from their indigenous knowledge system (IKS). The IPs, being forced into a new system of thinking mainly through formal education, now experience a greater struggle (Adonis \& Couch, 2017). In the consolidated study of the Episcopal Commission of Indigenous Peoples, it was revealed that IPs face discrimination in schools because the focus of the curriculum caters to the mainstream culture. This particular academic scenario poses a threat to IPs' cultural identity.

Furthermore, Reyes et al. (2017) found that some IPs in the Philippines had greater access to primary than to secondary education services. This situation was due to a lack of physical access to the learning environment. Unlike elementary schools situated in each barangay, only a few high schools are established in the municipalities. To address this, the government, through the Department of Education (DepEd), instituted the Indigenous Peoples Education Program (IPE) in 2011 to promote IKS and bring schools to the indigenous communities. This move has led to efforts in creating a culturally sensitive curriculum. In the study of Ganal (2017), IPE was critically examined. Following that report, the use of the Ottawa Indigenous Peoples Education Curriculum model was recommended as a framework for adoption, becoming the basis of the IP-based curriculum of a normal school in northern Luzon.

Similarly, Suazo and Montenegro (2018) investigated the preparedness of schools concerning the implementation of IPE. Regrettably, their results disclosed that schools lack the necessary resources such as materials and the involvement of elders. Further, there are no adept speakers of the indigenous language that 
would benefit from the teaching and learning process. This reality shows only that much remains to be done to improve services for IPs' education.

Looking into the status of IPs' education in the Philippines, it can be surmised that positive developments have been attributed to the government's move for inclusivity in education. This approach recognizes the need for all societal sectors to be empowered, and hence education is seen as a pivotal driving force. Nevertheless, in all these initial efforts being implemented, nothing is documented about IPs' educational profile. Moreover, little is known about how they transition from basic education to college life.

\subsection{College Preparedness in the Philippine Context}

The concept of college preparedness indicates the ability of Senior High School (SHS) graduates to be admitted to college and succeed without remediation in foundation courses. According to Conley (2007), college preparedness includes (1) knowledge of content, (2) application of content, and (3) cognitive strategies. These elements are interdependent and it is for students to hurdle these challenges of college life. Notably, college preparedness in the Philippines is a relatively recent concept brought on by the introduction of the K-12 program. Since higher education is one of the program's curricular exits, instructors, teachers, policymakers, and other stakeholders are involved in appraising SHS graduates' preparation in seeking tertiary education. In the same vein, the Commission on Higher Education (CHED) developed the College Readiness Standards (CRS) in 2011, specifying the skills required of graduates from the K-12 program in the General Education Courses (GEC) in order to ensure continuity of the skills acquired from the K-12 curriculum. CRS development aims to reduce remediation among higher education institutions (HEIs) and assess compliance with international quality standards (Commission on Higher Education, 2011). The CRS has seven fields of study: English, Literature, Filipino, Science, Mathematics, Social Studies, and Humanities. It consists of content and performance standards. Content standards refer to what students need to know, while performance standards pertain to what they can demonstrate with what they know. To date, there is no specific study on the college preparedness of IPs in the Philippines.

\subsection{Academic Variables Associated with College Preparedness}

Previous research has documented that certain academic profile variables may be associated with college preparedness, one of which is the type of school from where SHS graduates came. Means, Wang, Young, Peters, \& Lynch (2016) noted that a high school with a comprehensive Science, Technology, Engineering, and Mathematics (STEM) curriculum produces graduates applying for higher education with higher grade point average (GPA), more STEM extracurricular exposure, and higher educational ambitions. These academic attributes may prepare students better than their counterparts in facing the rigors of college life. On the one hand, in a Western setting, Study International Staff (2019) claimed that graduates from private schools tend to have higher admission rates from leading universities and better college and career outcomes than those from public schools. Also, graduates from Catholic high schools have a high probability of attending college (Altonji, Elder, \& Taber, 2005). As noted by Young, Hoffman, \& Chung (2017), "private schools were more focused on college preparedness initiatives than public schools."

Moreover, the track and strand taken in SHS appear to be valuable variables that could explain college preparedness. Relatedly, Magbag \& Raga (2020) claimed that the SHS strand proved to be a significant predictor for academic performance in college. Specifically, in the study of Mamolo (2019) on college Mathematics competency, graduates of STEM registered the highest performance among the strands, which may be attributed to their curricular exposure on problem solving, evidence valuation, and developing solutions through discovery and innovations.

In a careful inspection of the extant literature, a significant focus at present is placed on the use of GPA as a substantial measure of college preparedness (Cromwell, McClarty, \& Larson, 2013). According to Allensworth \& Clark (2020), a high school GPA is significantly related to college preparedness and success. This point is affirmed by previous researchers (Geiser \& Santelices, 2007; Hein, Smerdon, \& Sambolt, 2013; Hodara \& Lewis, 2017). These authors shared the notion that the higher the GPA of high school graduates, the more prepared they are for hurdling the academic challenges in college life.

Similarly, academic and nonacademic awards may have influence on college preparedness. The literature shows that awards serve as motivation for students to strive hard in their studies. Cerasoli, Nicklin, \& Ford (2014) assert that awards can boost self-confidence, leading to a sense of accomplishment and improvement. This stance is shared by Younghans (2016), who stated that recognition in the form of awards would foster a positive school culture, which in effect may drive better academic performance among learners.

Although there is no study to date directly relating it to college preparedness, students' participation in organizations becomes a significant academic variable in education studies, particularly when examining its influence on college learning outcomes and experience (Foubert \& Urbanski, 2006). This view is evident in previous research, with mixed results. For instance, Mayhew et al. (2016) claimed that student organizations' overall engagement yields a positive relationship with college retention rate, intellectual self-concept, and even cultural identity development. Also, Baker (2008) found that membership in academic organizations is positively linked to academic performance. Nonetheless, several researchers (Fazzlurrahman, Wijayati, \& Witjaksono, 2018; Leung, $\mathrm{Ng}$, \& Chan, 2011) found otherwise: the more students participated in organizations, the lower they performed in their academic studies.

In the same vein, involvement in co- and extracurricular activities is also a vital academic profile variable since it strengthens social interaction, leadership, and self-confidence (Marais, 2011). Cocurricular activities are undertaken relative to academic subjects such as Journalism and Science fair, while extracurricular activities are conducted outside school hours, such as Sports, Choral, and School club endeavors. With this, Reeves (2008) posits that involvement in these activities encourages students' learning and positively impacts academic performance. However, more recent studies have reported that extracurricular activities have no relationship with college preparedness (Craft, 2012; Hanks, 2018). 
Clearly, there are gaps in the literature about the association of certain academic profile variables with college preparedness. Hence, it is interesting to examine these variables considering the case of IPs in the Philippines. To enhance IPs' college preparedness, educators may find it necessary to be aware of the IPs' academic profile that may relate to and explain eventual academic success (Cromwell et al., 2013) in tertiary education.

\subsection{The Present Study}

Based on the foregoing contexts, the present study sought to (1) describe IPs' academic profile; (2) determine IPs' college preparedness; (3) compare IPs' college preparedness when grouped according to the type of SHS graduated from, as well as the track and strand in SHS; and (4) ascertain the association between respondents' college preparedness and their SHS GPA, number of academic and nonacademic awards received, participation in organizations, and involvement in co- and extracurricular activities.

In this regard, the following were the hypotheses deemed relative to the research objectives. First, IPs' college preparedness varies when grouped according to the type of SHS graduated from, and the track taken in SHS, and the strand taken in SHS. Second, there is a significant relationship between the college preparedness of IPs and their SHS GPA, the number of academic awards received, the number of nonacademic awards received, participation in the organization, and involvement in co- and extra-curricular activities.

\section{Methodology}

3.1. Research Design

The descriptive-correlational design was employed as this determines the association of academic profile variables and college preparedness of the IPs who graduated from the K-12 program. This research design is used to ascertain the interplay between and among variables. In essence, it examines the patterns in data but does not in any way prove any causative effect (Omair, 2015; Taskiran \& Baykal, 2019).

\subsection{Respondents}

Out of the 8,601 first-year students admitted for the School Year (SY) 2019-2020 in the study locale, 1,860 or $21.62 \%$ identified themselves as IPs by self-ascription. All these IPs were chosen to participate in the study. The majority of them were Itawes (59.9\%), followed by the Ibanag (29.5\%), Malaueg (3.5\%), Kalinga (3.4\%), Isneg $(2.3 \%)$, and Ivatan $(1.4 \%)$. Most of the respondents were female $(61 \%)$ and single $(98 \%)$. Their average age was $18.46 \pm 0.83$ years.

\subsection{Locale of the Study}

The study was conducted at a public university in the northern Philippines. As a comprehensive university, it consists of eight campuses with diverse curricular offerings. Its niche programs are Agriculture, Fisheries, Technology, Engineering, Business, Accountancy, Teacher Education, and Allied Health Sciences. As a public institution, it provides access to poor but deserving students from all societal sectors, including IP members.

\subsection{Research Instruments}

There were two primary data-gathering instruments used in the study. First was the Student Profile Questionnaire (SPQ) designed by the Discovery and Applied Research and Extension Trans-/interdisciplinary Opportunities (DARE TO) K-12 Research Grant of Cagayan State University (CSU). The tool was validated by social science experts and underwent pilot testing for nonrespondents. This instrument elicited the demographic and academic profile of the respondents.

The second instrument was the College Readiness Test (CRT) as developed by Tamayao et al. (2020). As a criterion-referenced test, it consists of 200 items that measure college preparedness in the seven core learning areas in the CRS, namely, English, Filipino, Literature, Mathematics, Science, Social Studies, and Humanities. It possesses a difficulty index of 65.64 , a discrimination index of 0.22 , and a distractor efficiency of $68.91 \%$. It is also a reliable tool as it has an inter-item consistency of $r=0.796$. Besides, it has the attributes of being contextualized and gender-fair. For its interpretation, examinees obtaining a raw score of at least 100 are considered college prepared whereas those getting scores lower than 100 are college unprepared.

\subsection{Data-gathering Procedure}

Foremost, permission to gather data was sought from the appropriate university officials. A brief orientation on ethical standards and protocols was given to all test administrators, to abide by the survey and test administration standards and ethics. The research team then developed the free and prior informed consent (FPIC) form, which the respondents signed before the survey and test administration. Aside from that, the respondents were informed of the study's purpose and the confidentiality of their identities and information.

The SPQ was administered to respondents during the enrolment period. On the other hand, the CRT was taken by the respondents two weeks after their enrolment. To uphold data integrity, the researchers strictly followed the guidelines in test administration, checking, and scoring, with the technical assistance of eight registered guidance counselors and eight licensed psychometricians.

\subsection{Data Analysis}

Frequencies, percentages, means, medians, standard deviations (SD), and interquartile ranges (IQR) were used to describe the study data. To compare respondents' college preparedness relative to their academic profile, Welch's analysis of variance (ANOVA) with Games-Howell post hoc test, and Mood's median test with Bonferroni adjustments, were utilized depending on whether the data on the groupings satisfied the assumptions of a parametric test. In addition, Kendall's tau- $b$ statistic was used to determine the association of college preparedness and selected ordinal academic profile variables. All statistical analyses were tested at the 0.05 level of significance using IBM SPSS version 23. 
4. Results

4.1. Academic Profile of Respondents

Table-1. Frequency and percentage distribution of respondents.

\begin{tabular}{|c|c|c|c|}
\hline & & Frequency & Percentage \\
\hline \multicolumn{4}{|l|}{ Type of SHS } \\
\hline & Public Science & 69 & 3.7 \\
\hline & Public Comprehensive & 991 & 53.3 \\
\hline & Public Vocational & 236 & 12.7 \\
\hline & Public Agriculture/Fishery (AF) & 58 & 3.1 \\
\hline & Private Sectarian & 253 & 13.6 \\
\hline & Private Nonsectarian & 253 & 13.6 \\
\hline \multicolumn{4}{|l|}{ Track taken } \\
\hline & Academic & 1440 & 77.4 \\
\hline & Technical Vocation & 404 & 21.7 \\
\hline & Sports & 11 & .6 \\
\hline & Arts and Design & 5 & .3 \\
\hline \multicolumn{4}{|c|}{ Academic Strand } \\
\hline & STEM & 476 & 33.1 \\
\hline & Humanities and Social Sciences (HUMSS) & 283 & 19.7 \\
\hline & Accountancy, Business, \& Management (ABM) & 220 & 15.3 \\
\hline & General Academic Strand (GAS) & 461 & 32.0 \\
\hline \multicolumn{4}{|c|}{ Technical/vocational Strand } \\
\hline & $\mathrm{AF}$ & 45 & 11.1 \\
\hline & Home Economics (HE) & 187 & 46.3 \\
\hline & Industrial Arts (IA) & 90 & 22.3 \\
\hline & Information Communication Technology (ICT) & 82 & 20.3 \\
\hline \multicolumn{4}{|c|}{ Sports Strand } \\
\hline & Safety and First Aid & 2 & 18.2 \\
\hline & Fitness Testing and Basic Exercise Programming & 2 & 18.2 \\
\hline & Sports Officiating and Activity Management & 3 & 27.3 \\
\hline & Fitness, Sports, and Recreational Leadership & 2 & 18.2 \\
\hline & Psychological Aspects of Sports and Exercise & 2 & 18.2 \\
\hline \multicolumn{4}{|c|}{ Arts and design Strand } \\
\hline & Visual Arts & 3 & 60.0 \\
\hline & Media Arts & 1 & 20.0 \\
\hline & Dance & 1 & 20.0 \\
\hline \multicolumn{4}{|c|}{ Academic awards received } \\
\hline & $\mathrm{O}$ & 814 & 43.8 \\
\hline & 1 & 806 & 43.3 \\
\hline & $>1$ & 240 & 12.9 \\
\hline \multicolumn{4}{|c|}{ Nonacademic awards received } \\
\hline & $\mathrm{O}$ & 1413 & 76.0 \\
\hline & 1 & 355 & 19.1 \\
\hline & $>1$ & 92 & 4.9 \\
\hline \multicolumn{4}{|c|}{ Participation in organizations } \\
\hline & $\mathrm{O}$ & 655 & 35.8 \\
\hline & 1 & 996 & 53.5 \\
\hline & $>1$ & 199 & 10.7 \\
\hline \multicolumn{4}{|c|}{ Cocurricular activities } \\
\hline & $\mathrm{O}$ & 1163 & 62.5 \\
\hline & 1 & 590 & 31.7 \\
\hline & $>1$ & 107 & 5.8 \\
\hline \multicolumn{4}{|c|}{ Extracurricular activities } \\
\hline & $\mathrm{O}$ & 876 & 47.1 \\
\hline & 1 & 853 & 45.9 \\
\hline & $>1$ & 131 & 7.0 \\
\hline \multicolumn{4}{|l|}{ SHS GPA } \\
\hline & an grade $=88.49 \pm 4.41$ & & \\
\hline
\end{tabular}

As shown in Table 1, the majority of respondents came from public/comprehensive SHS and took the academic track, while $<1 \%$ took the sports and arts and design tracks. Under the academic track, most IPs took the STEM strand while those who chose the Technical/Vocational track, in general, took the Home Economics strand. The majority of respondents did not receive any academic or nonacademic award, participated in only in one organization, and were not involved in co- or extracurricular activities. Regarding their SHS grade, respondents' mean grade was $88.49 \pm 4.41$, equivalent to Very Satisfactory based on the DepEd grading scale (DepEd Order No. 8, Series 2015).

Table 2 reveals that only $42.47 \%$ of IPs were college prepared, which implies that more than half could not master the content and performance standards in the seven learning areas defined in the CRS framework. Interestingly, more than half $(53.8 \%)$ of Ivatans were college prepared. 
4.2. College Preparedness of Respondents

Table 2. Frequency and percentage distribution of respondents based on their college preparedness.

\begin{tabular}{c|c|c|c|c}
\hline \multirow{2}{*}{ IP group } & \multicolumn{2}{|c|}{ Not prepared } & \multicolumn{2}{c}{ Prepared } \\
\cline { 2 - 5 } & Frequency & Percentage & Frequency & Percentage \\
\hline Ibanag & 322 & 58.7 & 227 & 41.3 \\
\hline Itawes & 632 & 56.7 & 482 & 43.3 \\
\hline Malaueg & 40 & 61.5 & 25 & 38.5 \\
\hline Ivatan & 12 & 46.2 & 14 & 53.8 \\
\hline Kalinga & 36 & 56.3 & 28 & 43.8 \\
\hline Isneg & 28 & 66.7 & 14 & 33.3 \\
\hline Over-all & 1,070 & 57.52 & 790 & 42.47 \\
\hline
\end{tabular}

4.3. Differentials in the College Preparedness of Respondents

Table 3. Comparison of college preparedness test scores relative to respondents' academic profiles.

\begin{tabular}{|c|c|c|c|c|c|c|}
\hline \multirow{2}{*}{$\frac{\text { Variable }}{\text { Type of SHS }}$} & \multirow{3}{*}{$\begin{array}{l}\text { Mean } \\
86.22^{\mathrm{A}}\end{array}$} & \multirow{3}{*}{$\begin{array}{c}\text { SD } \\
20.12\end{array}$} & \multirow[t]{2}{*}{ Median } & \multicolumn{3}{|c|}{ IQR } \\
\hline & & & & & & \\
\hline Public Agri-/Fishery & & & & & & \\
\hline Public Vocational & $91.47^{\mathrm{AB}}$ & 21.39 & & & & \\
\hline Public Comprehensive & $94.80^{\mathrm{BC}}$ & 19.77 & & & & \\
\hline Private Nonsectarian & $97.79^{\mathrm{CD}}$ & 21.87 & & & & \\
\hline Private Sectarian & $101.92^{\mathrm{D}}$ & 18.39 & & & & \\
\hline Public Science & $102.52^{\mathrm{CD}}$ & 24.07 & & & & \\
\hline \multicolumn{7}{|l|}{ Track } \\
\hline Sports & & & $75.00^{\mathrm{A}}$ & 62.00 & - & 91.00 \\
\hline Technical/Vocational & & & $86.00^{\mathrm{A}}$ & 74.00 & - & 99.75 \\
\hline Arts and Design & & & $91.00^{\mathrm{AB}}$ & 77.50 & - & 101.00 \\
\hline Academic & & & $99.00^{\mathrm{BC}}$ & 83.00 & - & 112.00 \\
\hline \multicolumn{7}{|l|}{ Academic strand } \\
\hline GAS & & & $92.00^{\mathrm{A}}$ & 80.00 & - & 105.00 \\
\hline HUMMS & & & $93.00^{\mathrm{A}}$ & 79.00 & - & 107.00 \\
\hline $\mathrm{ABM}$ & & & $101.00^{\mathrm{B}}$ & 86.00 & - & 114.00 \\
\hline STEM & & & $105.00^{\mathrm{C}}$ & 90.00 & - & 118.00 \\
\hline \multicolumn{7}{|l|}{ Technical/vocational strand } \\
\hline $\mathrm{AF}$ & & & $82.00^{\mathrm{A}}$ & 70.00 & - & 90.00 \\
\hline $\mathrm{HE}$ & & & $87.00^{\mathrm{A}}$ & 75.00 & - & 101.00 \\
\hline IA & & & $85.00^{\mathrm{A}}$ & 71.00 & - & 100.25 \\
\hline ICT & & & $84.00^{\mathrm{A}}$ & 75.00 & - & 98.75 \\
\hline
\end{tabular}

Note: *Means or medians of the same letter are not significantly different at the 0.05 level.

Source: Statistical Package for Social Sciences (SPSS) version 23.

Table 3 shows significant differences in students' mean college preparedness scores, in terms of the respondents' type of SHS, Welch's $F(5,292.689)=12.053, p<0.001$. The Games-Howell post hoc test results indicate that those who graduated from public agriculture/fishery or technical/vocational schools have significantly lower mean college preparedness scores than those who graduated from the other types of high school. Moreover, those who graduated from private sectarian schools had a significantly higher college preparedness score than public agriculture/fishery, vocational, and comprehensive schools. Graduates of public science and private schools did not significantly differ in their college preparedness.

A statistically significant difference was also found among the track taken by respondents on college preparedness: $x_{(3)}^{2}=88.591, p<0.001$. Specifically, results from the multiple comparison test with Bonferroni adjustment show that those who took the academic track had significantly higher college preparedness than those who took the sports and technical/vocational, but were not significantly different from those who took Arts and Design. Meanwhile, the college preparedness of those who took sports, technical/vocational, and Arts and Design were not significantly different from each other. There was also a significant difference in median college preparedness under the academic strand categories: $x_{(3)}^{2}=75.132, p<0.001$. Results from the multiple comparison test with Bonferroni adjustment indicate that those who took the GAS and HUMMS strand had significantly lower college preparedness than those under ABM and STEM, but were not significantly different from each other. Meanwhile, those who followed the STEM strand had significantly higher college preparedness than the other academic strand categories. There was no significant difference in the college preparedness of respondents who took the technical/vocational strand: $x_{(3)}^{2}=3.765, p=0.288$.

\subsection{Relationship between Academic Profile and College Preparedness of Respondents}

Table 4. Correlation between college preparedness and selected academic profiles.

\begin{tabular}{l|c|c}
\hline Variable & Correlation coefficient & $\boldsymbol{P}_{\text {value }}$ \\
\hline SHS GPA & $0.211^{* *}$ & $<0.001$ \\
\hline Number of academic awards & $0.230^{* *}$ & $<0.001$ \\
\hline Number of nonacademic awards & $0.051^{* *}$ & 0.007 \\
\hline Participation in organization & $0.047^{*}$ & 0.011 \\
\hline Involvement in cocurricular activities & $0.125^{* *}$ & $<0.001$ \\
\hline Involvement in extracurricular activities & 0.001 & 0.964 \\
\hline Note: Significant at *0.05 ** 0.01 & &
\end{tabular}

Note: Significant at *0.05, ** 0.01 . 
To investigate whether there was a statistically significant association between college preparedness and the academic profile variables shown in Table 4 , Kendall's tau- $b$ statistic was employed. The correlation results show that college preparedness was significantly associated with SHS GPA $\left(\tau_{\mathrm{b}}=0.211\right.$, $\left.p<0.05\right)$, number of academic awards $\left(\tau_{\mathrm{b}}=0.230, p<0.05\right)$, number of nonacademic awards $\left(\tau_{\mathrm{b}}=0.051, p<0.05\right)$, participation in organizations $\left(\tau_{\mathrm{b}}=0.047, p<0.05\right)$, and involvement in cocurricular activities $\left(\tau_{\mathrm{b}}=0.125, p<0.05\right)$. The direction of the correlations was positive, which means that respondents who had higher SHS GPA, more academic and nonacademic awards, greater participation in organizations, and more involvement in cocurricular activities tend to be more college prepared. However, the number of extracurricular activities was not significantly associated with college preparedness $\left(\tau_{\mathrm{b}}=0.001, p>0.05\right)$.

\section{Discussion}

The study reveals that the majority of the IPs who graduated from the K-12 program were college unprepared. This academic scenario may be a reflection of the overall struggle by IPs in the education setting because of the lack of access to educational services and resources (Adonis \& Couch, 2017; Victor \& Yano, 2015) since, generally, most come from disadvantaged communities (Cariño, 2012; De Vera, 2007). This finding could also be attributed to the lack of specific IPs' education design (Regaspi, 2017) due to a lack of necessary resources such as materials (Suazo \& Montenegro, 2018). Considering the situation of IPs as a marginalized sector, they have the propensity to be left behind academically as shown in the findings of the present study, where the majority did not receive any academic or nonacademic award, participated only in one organization, and were not involved in any co- or extracurricular activities.

Remarkably, most of the academic profile variables in the study were associated with college preparedness. It is interesting to note that IPs who graduated from private sectarian schools had significantly higher college preparedness test scores than those from public agriculture/fishery, technical/vocational, and comprehensive schools. One important reason for this is that private schools pay great attention to college preparedness efforts provided to their students (Young et al., 2017), which give an advantage to their graduates in regard to admission to tertiary education, and they therefore have better college and career outcomes (Study International Staff, 2019). Specifically, it has been reported that private sectarian schools, such as Catholic high schools, produce graduates who have a high probability of attending tertiary education (Altonji et al., 2005).

Another notable finding is that college preparedness varies in terms of the track taken in SHS. Those who pursued an academic track graduates were inclined to be more college prepared than those who took the sports and technical/vocational tracts. This scenario could be explained by the fact that the academic track has an enriched curriculum focusing on content and performance standards aligned with the CRS. At the same time, technical/vocational, sports, and arts and design tracks are practical skills based. Specifically, those who followed the STEM strand had significantly higher college preparedness than those in the other academic strand categories. This result is not surprising, since the literature has shown that STEM graduates generally have significant exposure to problem solving, evaluating evidence, and designing solutions through innovative undertakings such as research (Mamolo, 2019), which are necessary components of college preparedness (Conley, 2007).

Significantly, IPs with higher SHS GPA are more college prepared. The data affirm previous studies that GPA is a strong indicator of college preparedness (Allensworth \& Clark, 2020; Geiser \& Santelices, 2007; Hein et al., 2013; Hodara \& Lewis, 2017; Raju \& Schumacker, 2018). Put simply, since the CRT measures competencies in content and performance standards, it follows that those who perform better academically, as evidenced by their GPA, have the propensity to demonstrate better preparation in facing the academic challenges of college life.

In addition, academic (e.g., Best in Mathematics) and nonacademic awards (e.g., Leader of the Year) have been found to correlate with college preparedness. Those IPs with more awards tend to be better prepared for college life. This finding could be explained by the fact that awards are extrinsic incentives and serve as direct motivators (Frey \& Neckermann, 2009). They can boost performance (Cerasoli et al., 2014) and create a positive school culture (Younghans, 2016) that may foster college preparedness.

Participation in an organization also influences college preparedness. The more organizational memberships that IPs have, the more college prepared they are. Membership in academic organizations has been reported to relate favorably to academic performance (Baker, 2008) and to improve college retention rate, intellectual selfconcept, and cultural identity (Mayhew et al., 2016). Besides, involvement in cocurricular activities is positively linked to college preparedness. This result is consistent with the claim by Reeves (2008) that engagement in student activities enhances students' learning and positively impacts their academic performance. As posited by Astin's (1999) Involvement Theory, the more students participate in school-related activities the greater their academic and professional growth. In return, they may become college prepared because of the quality of their wide-ranging educational exposure.

\section{Conclusion}

The majority of IP graduates in the K-12 program, in the context of the present study, are college unprepared, which might provide a glimpse into their academic struggles in their transition from basic to tertiary education. As a marginalized and minority group, IPs still need to pay more attention to improving their academic profile and standing. Furthermore, this study proves that academic profile variables - such as type of SHS graduated from, track and strand taken in SHS, SHS GPA, number of academic and nonacademic awards received, participation in organizations, and involvement in cocurricular activities - significantly relate to college preparedness. Hence, educators in basic education need to enhance these academic variables to improve IPs' college preparedness. This move can be carried out by providing equal opportunities for IPs to participate in cocurricular activities and schoolbased organizations, and by encouraging them to strive hard to achieve academic and nonacademic awards. Also, for CHED's policy input, these academic profile variables may be considered as criteria in selecting applicants for possible IP scholarship grants in private higher educational institutions. Improving IPs' college preparedness with due consideration of their academic profile facilitates an increased likelihood of their being admitted to college and 
succeeding without remediation in college foundation courses. Ultimately, this effort may contribute to IPs' empowerment and enhancement of their cultural integrity in their country.

\section{Limitations and Further Studies}

The study's data are limited to first-year students of a public university enrolled in SY 2019-2020 in the northern Philippines. Only students belonging to the IP groups Itawes, Ibanag, Maluaeg, Kalinga, Isneg, and Ivatan participated in the research. Also, sports and arts tracks and their respective strands were not included in the hypothesis testing because of the very low numbers of samples or cases.

For future research, it would be interesting to consider IPs' cultural capital and college adjustment experience, with the inclusion of other IPs in northern Philippines and those enrolled in private universities. This future endeavor will provide additional baseline data and viable insights into IPs' transition from basic to tertiary education for policy input and other IP-driven educational initiatives.

\section{References}

Adonis, D., \& Couch, J. (2017). The trails to get there': Experiences of attaining higher education for Igorot Indigenous Peoples in the Philippines. Australian Journal of Adult Learning, 57(2), 197-2 16

Allensworth, E., \& Clark, K. (2020). High school GPA and ACT score as predictors of college completion: Examining assumptions about consistency across high schools. Educational Researcher, 49(3), 198-211. Available at: https://doi.org/10.3102/0013189X20902110.

Altonji, J. G., Elder, T. E., \& Taber, C. R. (2005). Selection on observed and unobserved variables: Assessing the effectiveness of Catholic schools. Journal of Political Economy, $113(1), 151-184$. Available at: https://doi.org/10.1086/426036.

Astin, A. W. (1999). Student involvement: A developmental theory for higher education. Journal of College Student Development, 40(5), 518529.

Baker, C. N. (2008). Under-represented college students and extracurricular involvement: The effects of various student organizations on academic performance. Social Psychology of Education, 11 (3), 273-298. Available at: https://doi.org/10.1007/s1 1218-007-9050-y.

Bereketeab, R. (2020). Education as an instrument of nation-building in postcolonial Africa. Studies in Ethnicity and Nationalism, 20(1), 7 1-90.

Cariño, J. (2012). Country technical notes on indigenous peoples' issues. Retrieved from International Fund for Agricultural Development (IFAD) website: Retrieved from: https://www.ifad.org/documents/38714170/40224860/philippines_ctn.pdf/aeofaa4a-2b65-40268d42-219db776c50d.

Cerasoli, C. P., Nicklin, J. M., \& Ford, M. T. (2014). Intrinsic motivation and extrinsic incentives jointly predict performance: A 40-year meta-analysis. Psychological Bulletin, 140(4), 980-1008. Available at: https://doi.org/10.1037/a0035661.

Commission on Higher Education. (2011). Commission en banc resolution No. 298-2011. Quezon City: CHED Central Office.

Conley, D. (2007). The challenge of college readiness. Educational Leadership, 64(7), 23-29.

Cornelio, J. S., \& De Castro, D. F. T. (2016). The state of indigenous education in the Philippines Today. In: Xing J., Ng P. (eds) Indigenous Culture, Education and Globalization. Berlin, Heidelberg: Springer.

Craft, S. W. (2012). The impact of extracurricular activities on student achievement at the high school level. Doctoral Dissertation.

Cromwell, A., McClarty, K. L., \& Larson, S. (2013). College readiness indicators. Pearson Bulletin, 25(1), 1-8.

De Vera, D. (2007). Indigenous peoples in the Philippines: A country case study. Paper presented at the Paper Presented at the RNIP Regional Assembly.

Fazzlurrahman, H., Wijayati, D. T., \& Witjaksono, A. D. (2018). A measurement of performance: Student involvement in organization and campus environment. International Journal of Educational Research Review, 3(4), 11-22.

Foubert, J. D., \& Urbanski, L. A. (2006). Effects of involvement in clubs and organizations on the psychosocial development of first-year and senior college students. Journal of Student Affairs Research and Practice, 43(1), 166-182.

Frey, B., \& Neckermann, S. (2009). Awards: A disregarded source of motivation. Rationality, Markets and Morals, 11(1), $177-182$.

Ganal, N. (2017). The University of Ottawa indigenous peoples education curriculum model: basis in the development of indigenous peoples education curriculum for PNU-North Luzon. The Normal Lights, 1 1(1), 198-234.

Geiser, S., \& Santelices, S. V. (2007). Validity of high-school grades in predicting student success beyond the freshman year: High-school record vs. standardized tests as indicators of four-year college outcomes (Research \& Occasional Paper Series No. CSHE.6.07). Berkeley: University of California, Berkeley, Center for Studies in Higher Education.

Hanks, C. (2018). Relationship between extracurricular activity involvement and student success among high school students in accelerated academic curricula. Doctoral Dissertation.

Hein, V., Smerdon, B., \& Sambolt, M. (2013). Predictors of postsecondary success. Washington, DC: American Institutes for Research, College \& Career Readiness \& Success Center.

Hodara, M., \& Lewis, K. (2017). How well does high school grade point average predict college performance by student urbanicity and timing of college entry? (REL 2017-250). Washington, DC: U.S. Department of Education, Institute of Education Sciences, National Center for Education Evaluation and Regional Assistance, Regional Educational Laboratory Northwest.

Idris, F., Hassan, Z., Ya'acob, A., Gill, S. K., \& Awal, N. A. M. (2012). The role of education in shaping youth's national identity. ProcediaSocial and Behavioral Sciences, 59(1), 443-450.

Kingdom, E., \& Maekae, J. (2013). The role of education in national development: Nigerian experience. European Scientific Journal, 9(28), $312-$ 320.

Leung, C.-H., Ng, C. W. R., \& Chan, P. O. E. (2011). Can co-curricular activities enhance the learning effectiveness of students?: An application to the sub-degree students in Hong Kong. International Journal of Teaching and Learning in Higher Education, 23(3), 329341.

Magbag, A., \& Raga, R. (2020). Prediction of college academic performance of senior high school graduates using classification techniques. International Journal of Scientific $\Xi^{2}$ Technology Research, 9(4), 2104-2 109.

Mamolo, L. (2019). Analysis of senior high school students' competency in general mathematics. Universal Journal of Educational Research, 7(9), 1938-1944. Available at: https://doi.org//10.13189/ujer.2019.070913.

Marais, P. (2011). The significance of student teacher's involvement in co-curricular activities. International Journal of e-learning security, 1(3/4), 81-88. Available at: https://doi.org/10.20533/ijels.2046.4568.2011.0010.

Mayhew, M. J., Rockenbach, A. H., Bowman, N. A., Seifert, T. A., Wolniak, G. C., Pascarella, E., \& Terenzini, P. T. (2016). How college affects students: 21st-century evidence that higher education works (Vol. 3). San Francisco, CA: Jossey-Bass.

Means, B., Wang, H., Young, V., Peters, V. L., \& Lynch, S. J. (2016). STEM-focused high schools as a strategy for enhancing readiness for postsecondary STEM programs. Journal of Research in Science Teaching, 53(5), 709-736.

Omair, A. (2015). Selecting the appropriate study design for your research: Descriptive study designs. Journal of Health Specialties, 3(3), 153156. Available at: https://doi.org/10.4103/1658-600x.159892.

Pe-Pua, R., \& Protacio-Marcelino, E. A. (2000). Sikolohiyang Pilipino (Filipino psychology): A legacy of Virgilio G. Enriquez. Asian Journal of Social Psychology, 3(1), 49-71.

Raju, D., \& Schumacker, R. (2018). Exploring student characteristics of retention that lead to graduation in higher education using data mining models. Journal of College Student Retention: Research, Theory \& Practice, 16(4), 563-591. Available at: https://doi.org//10.2190/cs.16.4.e.

Reeves, D. (2008). The learning leader/The extracurricular advantage. Educational Leadership, 66(1), 86-87.

Regaspi, R. (2017). Determinants and problems in the completion of tertiary education of indigenous peoples in the Philippines. Journal of Social Sciences and Humanity Studies, 4(5), 1-9. 
Reyes, C. M., Mina, C., \& Asis, R. (2017). Inequality of opportunities among ethnic groups in the Philippines. Discussion Paper Series No. $2017-42$.

Sicat, L., \& David, M. E. (2016). Performance in basic mathematics of indigenous students. Universal Journal of Educational Research, 4(2), 320-325. Available at: https://doi.org/10.13189/ujer.2016.040202.

Study International Staff. (2019). The pros and cons of private school education. Retrieved from https://www.studyinternational.com/news/benefit-private-schools/.

Suazo, M. L. S., \& Montenegro, G. (2018). Implementation of a culture-based education. American International Journal of Research in Humanities, Arts and Social Sciences, 22(1), 146-152.

Tamayao, A., Vecaldo, R., Asuncion, J. E., Mamba, M., Paat, F. M., \& Pagulayan, E. (2020). Design and validation of the college readiness test for Filipino K to 12 graduates. International Journal of Higher Education, 9(2), 209-224.

Taskiran, G., \& Baykal, U. (2019). Nurses' disaster preparedness and core competencies in Turkey: A descriptive correlational design. International Nursing Review, 66(2), 165-175.

Torraco, R. (2018). Economic inequality, educational inequity, and reduced career opportunity: A self-perpetuating cycle. New Horizons in Adult Education, \& Human Resource Development, 30(1), 19-29. Available at: https://doi.org/10.1002/nha3.20206.

United Nations Development Programme. (2010). Indigenous peoples in the Philippines: United Nations development programme fast facts. Retrieved from: https://www.ph.undp.org/content/philippines/en/home/library/democratic governance/FastFacts-IPs.html

Victor, M. L., \& Yano, B. (2015). Actualizing the inclusion of indigenous peoples' rights in education: A policy initiative in the Philippines. Human Rights Education in Asia-Pacific, 6(1), 133-161.

Wa-Mbaleka, S. (2013). Quality education for native filipinos: A Phenomenological case study of indigenous learners. IAMURE International Journal of Social Sciences, 6, 1-18. Available at: http://dx.doi.org/10.7718/ijss.v6i1.510.

Young, D. G., Hoffman, D. E., \& Chung, J. K. (2017). Exploring college and career readiness in South Carolina secondary schools. National Resource Center Working Paper No. 2. Columbia, SC: University of South Carolina, National Resource Center for the First-Year Experience and Students in Transition.

Younghans, M. (2016). Recognizing student success: Creating a positive culture for students [Blog Post]. Retrieved from: https://blog.nassp.org/2016/08/30/recognizing-student-success-creating-a-positive-culture-forstudents/\#: :text=Watching\%20students\%20grow\%20and\%20accomplish,culture\%20where\%20students\%20feel\%20valued. 